\title{
Validating methods for estimating endocranial volume in individual red deer (Cervus elaphus)
}

Corina J. Logan*a (itsme@corinalogan.com) and Tim H. Clutton-Brock (thcb@cam.ac.uk)

Department of Zoology, University of Cambridge, Downing Street, Cambridge CB2 3EJ, UK

*Corresponding author.

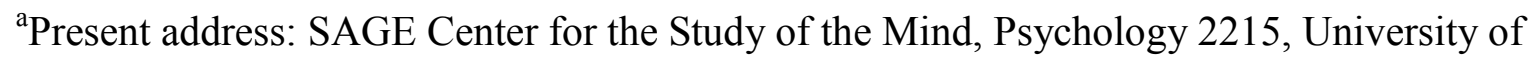

California, Santa Barbara, CA 93106-9660, USA, phone: 001-805-893-5006, FAX: 001-805-8933228.

\begin{abstract}
Comparing brain sizes is a key method in comparative cognition and evolution. Brain sizes are commonly validated by interspecific comparisons involving animals of varying size, which does not provide a realistic index of their accuracy for intraspecific comparisons. Intraspecific validation of methods for measuring brain size should include animals of the same age and sex to ensure that individual differences can be detected in animals of similar size. In this study we compare three methods of measuring the endocranial volume of 33 red deer skulls to investigate the accuracy of each method. Methods for estimating endocranial volume included scanning each skull using computerised tomography (CT) and quantifying the volume with OsiriX software, filling the cranium with glass beads and measuring the bead volume, and linear measurements (length, width, and height) of the cranium using calipers. CT scan volumes were highly correlated with results from the bead method, but only moderately correlated with the linear method. This study illustrates the importance of validating intraspecies measurement methods, which allows for the accurate interpretation of results.
\end{abstract}

Keywords: bead-filling; Cervus elaphus; CT scan; endocranial volume; linear; methods 


\section{Introduction}

Brain size differences within and across species have been a matter of great interest to researchers studying comparative cognition for over a century (Harvey and Krebs, 1990; Gould, 1996). Although brain size is highly heritable (Cheverud et al., 1990; Bartley et al., 1997; Rogers et al., 2007), some variation is due to life history, social, and ecological factors. Differences in mating strategy and sex (Iwaniuk, 2001; Kolm et al., 2009; Kotrschal et al., 2012), environmental enrichment (Rosenzweig and Bennett, 1969), social status (Smith et al., 2010), and navigation (Maguire et al., 2000) can enlarge the whole brain or particular regions due to the different environmental and cognitive demands placed on particular categories of individuals. One issue in this field is that brain size measurement methods are not standardised and are not usually validated for their accuracy, which poses a problem particularly for intraspecies comparisons because individual differences are more difficult to detect among animals of the same age and sex (Healy and Rowe, 2007). The method by which brain size is measured or approximated is crucial for reaching conclusions about its evolution and development. The growing interest in determining the causes of brain size variation warrants an investigation into the relationship among measurements and a validation of their accuracy. Here, we validate methods for measuring endocranial volume, a common approximation for brain size (Iwaniuk \& Nelson, 2002), in red deer (Cervus elaphus).

The purpose of this study was to compare endocranial volumes in red deer as measured by CT scans, beads, and linear dimensions to determine which methods are accurate enough for use in the field. The most widely used method of estimating endocranial volume involves filling the cranium with beads (or other materials such as mustard seeds or lead shot), the volume of which is then measured with a graduated cylinder or by weighing the beads and converting the weight to volume (e.g., Isler et al., 2008; Iwaniuk and Nelson, 2002). Linear measurements of the external skull (e.g., length, width, and height) can also be used to estimate endocranial volume (e.g.. Waitzman et al., 
1992). Measuring endocranial volume from computerised tomography (CT) scans using software is becoming a more prominent method as the technology becomes more accessible and affordable (e.g., Waitzman et al., 1992; Sakai et al. 2011). Endocranial volume via CT scans correlates well with external cranial measures in children (Coqueugniot and Hublin, 2012), and with the seedfilling method in human and non-human primates (Conroy and Vannier, 1986) and carnivores (Swanson et al., 2012).

\section{Materials and Methods}

We measured the endocranial volumes of 33 adult red deer skulls (18 male, 15 female) from Norma Chapman's private collection in the UK and from the Grahame Clark Laboratory for Zooarchaeology at the University of Cambridge using CT scans, the bead method, and linear measurements (note to editor: data will be accessible online at datadryad.org. We can upload the data as soon as the ms has been accepted and can then reference the database here.). Deer were considered adults if they were two years of age or older at the time of death (age range: 2.25-27.5 years, mean=5.1, standard deviation=5.0). The age at death was known for most skulls $(\mathrm{n}=24)$. The remaining nine skulls were included in the analysis because the total skull length (a proxy for body size) was greater than that of the youngest skull of known age. All data were normally distributed according to the Anderson-Darling normality test ( $\mathrm{p}>0.05)$. All within-method measurements were highly repeatable (see Appendix). Methods were compared against each other using Welch's t-tests for independent samples (assuming unequal variances) to determine whether the means significantly differed. Samples were considered independent because each method for estimating endocranial volume was unique.

\subsection{Computerised Tomography (CT) Method}

We scanned skulls at Cambridge Radiology Referrals using a Toshiba Aquilon 16-slice CT scanner (1mm slices, $140 \mathrm{~mm}$ fov, $100 \mathrm{kV}$ tube voltage, $80 \mathrm{~mA}$ current, with a bone algorithm to sharpen the 
contrast between bone and cavity), and calculated endocranial volumes from the scans in DICOM format using OsiriX 32-bit version 4.1.2 (Rosset et al., 2004). We defined the endocranial space from the rostral end of the endocranium (including the olfactory bulbs) to the occipital bone at the caudal end and across the superior surface of the opening of the foramen magnum, and used volume calculation protocols from van der Vorst et al. (2010; we used a computer mouse rather than a digital pen to trace the intracranial line). When bones on one side of the skull were missing, we copied the intracranial polygon from the intact side to the opposite side. Slices were set to a thickness of $2.6 \mathrm{~mm}$ and every third slice was analysed (Sahin et al., 2008). We considered the CT scanning method to represent the actual endocranial volume, to which the other two methods were compared for accuracy, because the intracranial surface was traced precisely and at sufficient intervals to obtain an accurate calculation. We thus compared the CT scanning data to those obtained with the other two methods using Pearson's Product Moment Correlation tests in R 2.15.0 (R Development Core Team, 2011).

\subsection{Bead Method}

We estimated endocranial volume by pouring $2 \mathrm{~mm}$ diameter soda lime glass beads into the cranium until full, shaking it until the beads settled, adding more beads, and repeating the process until the shaken bead level reached just below the four holes in the foramen magnum. We then poured the beads from the skull into a graduated cylinder and read the volume in $\mathrm{ml}$. We filled holes in the cranium with cotton wool to prevent the beads from leaking and applied masking tape to severely broken skulls to maintain the original cranial shape.

\subsection{Linear Measurement Method}

We estimated endocranial volume using callipers to measure external cranial length (L), width (W), and height $(\mathrm{H})$ as delineated by Finarelli (2006), taking three measurements of each variable and using the average in the analysis. Endocranial volume $\left(\mathrm{cm}^{3}\right)$ was calculated as $\mathrm{LxWxH}$ (eq. 1). 
Finarelli (2011) established an equation that accurately estimates brain volume across non-bovid ruminant Artiodactylid species, a category to which red deer belong, using the external cranial width for each individual: $\operatorname{Ln}[$ brain volume] $=2.6616(\operatorname{Ln}[\mathrm{W}])-6.2722$ (eq. 2). We applied this equation to the skulls in this sample to determine whether it also accurately estimates endocranial volumes within a species.

\section{Results}

Endocranial volume measured using the bead method was highly correlated with results obtained from the CT scan method $(\mathrm{r}=0.9552, \mathrm{t}=17.97, \mathrm{df}=31, \mathrm{p}<0.001$; Figure 1$)$. The linear measurement results were less strongly correlated with $\mathrm{CT}$ scan results $(\mathrm{r}=0.8361, \mathrm{t}=8.49, \mathrm{df}=31, \mathrm{p}<0.001)$, and the correlation was the weakest for Finarelli's equation vs. the CT scan method $(r=0.8085, t=7.60$, $\mathrm{df}=31, \mathrm{p}<0.001 ;$ Figure 1).

Results were similar for the bead vs. CT methods when analysing according to sex, but correlations greatly declined for the linear and Finarelli equation methods for both sexes (females: bead vs. CT $\mathrm{r}=0.8976, \mathrm{t}=7.34, \mathrm{df}=13, \mathrm{p}<0.001$; linear vs. $\mathrm{CT} \mathrm{r}=0.5105, \mathrm{t}=2.14, \mathrm{df}=13, \mathrm{p}=0.05$; Finarelli vs. $\mathrm{CT}$ $\mathrm{r}=0.4179, \mathrm{t}=1.65, \mathrm{df}=13, \mathrm{p}=0.12$. Males: bead vs. $\mathrm{CT} \mathrm{r}=0.9695, \mathrm{t}=15.83, \mathrm{df}=16, \mathrm{p}<0.001$; linear vs. CT r $=0.6803, \mathrm{t}=3.71, \mathrm{df}=16, \mathrm{p}=0.002$; Finarelli vs. $\mathrm{CT} \mathrm{r}=0.6168, \mathrm{t}=3.13, \mathrm{df}=16, \mathrm{p}=0.006$ ).

Comparing methods against each other, only the endocranial volume means from the CT scans and the bead methods were similar $(\mathrm{t}=-1.78, \mathrm{df}=64, \mathrm{p}=0.08)$. All other means were significantly different in pairwise tests (CTxLinear $\mathrm{t}=28.00, \mathrm{df}=33, \mathrm{p}<0.001$; CTxFinarelli $\mathrm{t}=-4.29$, $\mathrm{df}=56$, $\mathrm{p}<0.001$; BeadxLinear $\mathrm{t}=-28.34, \quad \mathrm{df}=33, \mathrm{p}<0.001 ;$ BeadxFinarelli $\mathrm{t}=2.96, \quad \mathrm{df}=54, \quad \mathrm{p}=0.005$; LinearxFinarelli $\mathrm{t}=-28.71, \mathrm{df}=35, \mathrm{p}<0.001)$. 


\section{Discussion}

Although all of these methods may function for interspecies comparisons, only the bead and CT scanning methods for estimating the endocranial volume of red deer are accurate enough to compare individuals of the same age and sex. Linear measures were not accurate enough to ensure reliable results. While Finarelli's (2011) equation for non-bovid ruminant Artiodactyls accurately compares interspecies brain volumes, it is less accurate when applied to analyses at the intraspecies level. Intraspecies comparisons require a much finer resolution to detect individual differences. The brain size estimates from the Finarelli equation deviate on average $20 \mathrm{ml}$ from the equivalent CT scan results for red deer, however, this difference should not affect the interspecies comparisons where there are generally more than $20 \mathrm{ml}$ differences between species (Finarelli, 2011: Appendix 1). Comparing methods to each other, only the endocranial volume measurements from the CT scans and bead methods produced similar results.

Validating measurements for estimating brain size is a crucial component in the investigation of intraspecific and interspecific variation in brain size. The method validation conducted in this paper will ensure that the proper method is used in future investigations of the factors influencing absolute brain size variation in red deer.

\section{Acknowledgments}

We are grateful to Norma and Donald Chapman for allowing this study to be carried out on their red deer skull collection; Suzanne Pilaar Birch for access to an additional skull from the Grahame Clark Laboratory for Zooarchaeology at the University of Cambridge; Sharleen Sakai for CT scanning recommendations; Matt Mason for a software demonstrations; Loeske Kruuk, Josephine Pemberton, and Dieter Lukas for advice; Neeltje Boogert for manuscript feedback; Uri Grodzinski for transporting skulls; Joy Archer for finding a CT scanner; Paddy Mannion at Cambridge Radiology Referrals for scanning the skulls; Mathew Lowe and Rob Asher for discussions and 
calipers; Neal Maskell and Nanna Evers for lab equipment; and to an anonymous reviewer for useful comments on an earlier draft of this manuscript.

\section{References}

Bartley, A.J., Jones, D.W., Weinberger, D.R., 1997. Genetic variability of human brain size and cortical gyral patterns. Brain 120, 257-269.

Cheverud, J.M., Falk, D., Vannier, M., Konigsberg, L., Helmkamp, R.C., Hildebolt, C., 1990. Heritability of brain size and surface features in rhesus macaques (Macaca mulatta). J. Hered. 81, 51-57.

Conroy, G.C, Vannier, M.W., 1986 Three-dimensional computer imaging: some anthropological applications, in: Lee, P.C., Else, J.G. (Eds.), Primate Evolution, Volume 1. Cambridge University Press, Cambridge, pp. 211-221.

Coqueugniot, H., Hublin, J.J. 2012. Age-relate changes of digital endocranial volume during human ontogeny: results from an osteological reference collection. Am. J. Phys. Anthropol. 147, $312-318$.

Finarelli, J.A., 2006. Estimation of endocranial volume through the use of external skull measures in the Carnivora (Mammalia). J. Mammal. 87, 1027-1036.

Finarelli, J.A., 2011. Estimating endocranial volume from the outside of the skull in Artiodactyla. J. Mammal. 92, 200-212.

Gould, S.J., 1996. The Mismeasure of Man, revised. W. W. Norton \& Company, New York.

Harvey, P.H., Krebs, J.R., 1990. Comparing brains. Science 249, 140-146.

Healy, S.D., Rowe, C., 2007. A critique of comparative studies of brain size. Proc. Biol. Sci. 274, 453-464.

Isler, K., Kirk, E.C., Miller, J.M.A., Albrecht, G.A., Gelvin, B.R., Martin, R.D., 2008. Endocranial volumes of primate species: scaling analyses using a comprehensive and reliable data set. J. Hum. Evol. 55, 967-978. 
Iwaniuk, A.N., 2001. Interspecific variation in sexual dimorphism in brain size in Nearctic ground squirrels (Spermophilus spp.). Can. J. Zool. 79, 759-765.

Iwaniuk, A.N., Nelson, J.E., 2002. Can endocranial volume be used as an estimate of brain size in birds? Can. J. Zool. 80, 16-23.

Kolm, N., Gonzalez-Voyer, A., Brelin, D., Winberg, S., 2009. Evidence for small scale variation in the vertebrate brain: mating strategy and sex affect brain size and structure in wild brown trout (Salmo trutta). J. Evol. Biol. 22, 2524-2531.

Kotrschal, A., Räsänen, K., Kristjánsson, B. K., Senn, M., \& Kolm, N., 2012. Extreme sexual brain size dimorphism in sticklebacks: a consequence of the cognitive challenges of sex and parenting? PLoS ONE 7, e30055.

Maguire, E. A., Gadian, D. G., Johnsrude, I. S., Good, C. D., Ashburner, J., Frackowiak, R. S., Frith, C. D., 2000. Navigation-related structural change in the hippocampi of taxi drivers. Proc. Natl. Acad. Sci. 97, 4398-4403.

R Development Core Team, 2011. R: a Language and Environment for Statistical Computing. R Foundation for Statistical Computing, Vienna, Austria.

Rogers, J., Kochunov, P., Lancaster, J., Shelledy, W., Glahn, D., Blangero, J., Fox, P., 2007. Heritability of brain volume, surface area and shape: an MRI study in an extended pedigree of baboons. Hum. Brain Mapp. 28, 576-583.

Rosenzweig, M.R., Bennett, E.L., 1969. Effects of differential environments on brain weights and enzyme activities in gerbils, rats, and mice. Dev. Psychobiol. 2, 87-95.

Rosset, A., Spadola, L., Ratib, O., 2004. OsiriX: an open-source software for navigating in multidimensional DICOM images. J. Digit. Imaging 17, 205-216.

Sakai, S.T., Arsznov, B.M., Lundrigan, B.L., Holekamp, K.E., 2011. Virtual endocasts: an application of computed tomography in the study of brain variation among hyenas. Ann. NY. Acad. Sci. 1225, E160-E170. 
Sahin, B., Mazonakis, M., Akan, H., Kaplan, S., Bek, Y., 2008. Dependence of computed tomograpy volume measurements upon section thickness: an application to human dry skulls. Clin. Anat. 21, 179-485.

Smith, A.R., Seid, M.A., Jiménez, L.C., Wcislo, W.T., 2010. Socially induced brain development in a facultatively eusocial sweat bee Megalopta genalis (Halictidae). Proc. R. Soc. Lond. B 277, $2157-2163$.

Swanson, E.M., Holekamp, K.E., Lundrigan, B.L., Arsznov, B.M., Sakai, S.T., 2012. Multiple determinants of whole and regional brain volume among terrestrial carnivorans. PLoS ONE 7, e38447.

van der Vorst, J.R., van Dam, R.M., van Stiphout, R.S.A., van den Broek, M.A., Hollander, I.H., Kessels, A.G.H., Dejong, C.H.C., 2010. Virtual liver resection and volumetric analysis of the future liver remnant using open source image processing software. World J. Surg. 34, 24262433.

Waitzman, A.A., Posnick, J.C., Armstrong, D.C., Pron, G.E., 1992. Craniofacial skeletal measurements based on computed tomography: Part I. Accuracy and reproducibility. Cleft Palate-Cran. J. 29, 112-117. 


\section{Figure Legend}

Fig. 1. Comparison of endocranial volume results obtained with the CT scan method (Volume CT) with results from the bead method (A), the linear measurement method (B), and Finarelli's equation based on skull width (C). 


\section{APPENDIX: Intra-observer Reliability}

All data were collected by Corina Logan. Intra-observer reliability analyses were conducted to determine the repeatability of each type of measurement.

\section{Methods}

Intra-observer reliability was carried out on nine skulls: the first five male and first four female skulls listed on the data sheet. A second set of measurements on these skulls were collected on a different day from the day of the original measurements. CT scans were analysed in OsiriX with an additional region of interest (ROI) in a different colour that began on a different slice from the original analysis to ensure the original ROI was not visible when making the intra-observer reliability ROI. Data were analysed using Pearson's Product-Moment Correlations to determine how well the two sets of measurements on the same skulls correlated within each method.

\section{Results and Discussion}

The two sets of measurements for each method were highly correlated and had similar means and standard deviations (Table A1). Thus, there was a high degree of intra-observer reliability for all methods used in this study.

Table A1. Comparing two sets of volume measurements on each skull for each method to determine the intra-observer reliability of that particular method using Pearson's Product-Moment Correlations.

\begin{tabular}{|c|c|c|c|}
\hline \multirow[b]{2}{*}{ Method } & \multirow[b]{2}{*}{ Correlation } & \multicolumn{2}{|c|}{ Mean \pm Standard Deviation } \\
\hline & & Set 1 & Set 2 \\
\hline CT volume & $\mathrm{r}=1.00, \mathrm{t}=28.98, \mathrm{df}=7, \mathrm{p}<0.001$ & $370 \pm 39$ & $373 \pm 39$ \\
\hline Bead volume & $\mathrm{r}=0.99, \mathrm{t}=19.82, \mathrm{df}=7, \mathrm{p}<0.001$ & $362 \pm 37$ & $361 \pm 37$ \\
\hline Linear volume & $\mathrm{r}=1.00, \mathrm{t}=38.33, \mathrm{df}=7, \mathrm{p}<0.001$ & $1491 \pm 316$ & $1489 \pm 309$ \\
\hline
\end{tabular}



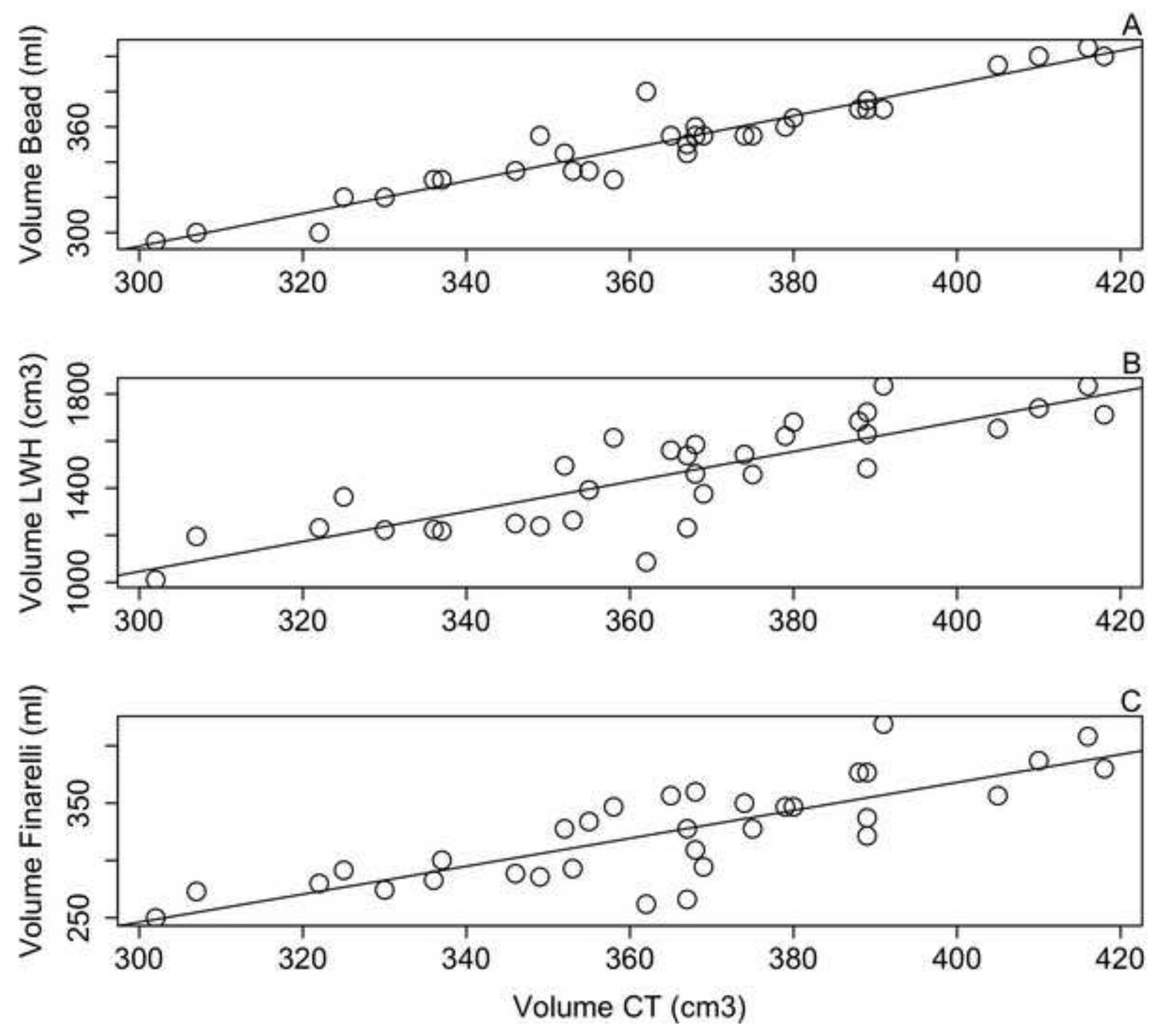